\title{
Evaluating the Efficacy of the Treatment with Benfotiamine and Alpha-lipoic Acid in Distal Symmetric Painful Diabetic Polyneuropathy
}

\author{
AMORIN REMUS POPA ${ }^{1,2}$, SIMONA BUNGAU1*, COSMIN MIHAI VESA ${ }^{1,2 *}$ ANDREI CRISTIAN BONDAR ${ }^{1,2}$, CARMEN PANTIS ${ }^{1,2}$, \\ OCTAVIAN MAGHIAR ${ }^{1,2}$, IOANA ALINA DIMULESCU (NICA) ${ }^{3}$, DELIA CARMEN NISTOR CSEPPENTO ${ }^{1}$, MARIUS RUS ${ }^{1,2}$ \\ 'University of Oradea, Faculty of Medicine and Pharmacy, 10, 1 Decembrie Sq., 410073, Oradea, Romania \\ ${ }^{2}$ Clinical County Emergency Hospital of Oradea, 65 Gheorghe Doja Str., 410169, Oradea, Romania \\ ${ }^{3}$ Politehnica University of Bucharest, Faculty of Applied Chemistry and Materials Science, 1-7 Gh. P. Polizu Str., 011061, Bucharest, \\ Romania
}

\begin{abstract}
Distal symmetric painful diabetic neuropathy is the most frequent clinical form of diabetic neuropathy. The condition appears as a result of alteration of the structure and function of nervous fibres as a consequence of hyperglycaemia. Hyperglycaemia determines the metabolism of glucose on alterative pathways and generates increased oxidative stress, mechanisms that cause an accelerated apoptosis of the neurons and a high intensity of lipid peroxidation. Pathogenic treatment of diabetic neuropathy includes limited options, two of them are: Benfotiamine (inhibits the metabolism of glucose on hexosamine pathway, reducing the formation of advanced glycosylation end products) and alpha-lipoic acid (has a scavenger effect on free radical species). The study included 120 patients with distal symmetric painful diabetic neuropathy randomized in 3 treatment groups. We evaluated the effect of oral administration for 8 weeks of Benfotiamine in a dosage of $300 \mathrm{mg} /$ day in monotherapy, of alpha-lipoic acid in a dosage of $600 \mathrm{mg} /$ day in monotherapy, respectively of both -in combined therapy - on the parameters that are used to determine the severity of distal symmetric painful diabetic neuropathy: Diabetic Neuropathy Symptoms score, Neuropathy Disability Score and the intensity of lower limb pain on the visual analogue pain scale. All the three therapies were effective with a statistically significant improvement of these parameters, but the combined therapy with alpha-lipoic acid and Benfotiamine was superior to the monotherapy with alpha-lipoic acid or Benfotiamine.
\end{abstract}

Keywords: pathogenic treatment of diabetic neuropathy, Diabetic Neuropathy Symptoms score, Neuropathy Disability Score, alpha-lipoic acid, Benfotiamine.

Diabetic neuropathy represents an important cause of morbidity and mortality because of the complications it generates, such as lower limb ulcerations (leading to amputations or balance problems [1] that can be later the cause of traumatisms produced by falling, etc.) It was estimated that after 20 years of diabetes evolution, the prevalence of neuropathy is almost 50\% [2]. Distal symmetric painful diabetic neuropathy (DSPDN) is the most frequent clinical form of diabetic neuropathy and it represents a chronic, symmetric dysfunction of the long peripheral nerve fibres of the lower limbs. The specific symptoms include numbness, pain, tingling, and sensation of burns or prickling in the lower limbs [3-7]. The first symptoms that appear, the pain and the burning sensation are caused by a destruction of thin nervous fibres, the pain and the burning sensation [8]. The pain is described by the patient as a burn or as a prickling, it is accompanied by hyperalgesia (it becomes more severe at the contact with stimuli that should not produce pain, like the sock or the shoe) [8]. The destruction of the thick nervous fibre manifests with numbness and tingling sensation at the level of the lower limbs. In this late stage the protective pain perception is lost, the patient does not feel if he suffers minor injuries to the lower limbs, which leads in time to lower plantar diabetic ulcers [8].

Hyperglycaemia represents the most important factor in the pathogenesis of diabetic neuropathy [3-7] and is the main cause of the physio-pathological mechanisms that determine the appearance of diabetic neuropathy: increased influx on the polyol pathway, accumulation of glycosylation end products, increased influx on the hexosamine pathway, activation of protein-kinase $C$ and oxidative stress [9]. The excess of glucose metabolized on the polyol pathway leads to a decrease in NADPH concentration and as a consequence of glutathione concentration, this way glutathione antioxidant activity is diminished. Advanced glycosylation end products through binding on specific receptors activate intracellular pathways that increase oxidative stress, the activation of protein-kinase $\mathrm{C}$ decreases the tissue vascularization, promotes the pro-inflammatory gene expression, the metabolism of glucose on the hexosamine pathway accentuates even more the vascular dysfunction and oxidative stress [10-12]. Therefore, the metabolism of glucose on these alternative pathways generates a mitochondrial dysfunction that disrupts ATP production; as a result, the energy necessary for cell survival is no longer available. Furthermore, the mitochondrial dysfunction initiates the activation of apoptotic pathways responsible for peripheral nerves apoptosis.

If the diagnosis of DSPDN is established, there are two treatment possibilities: pathogenic treatment (that acts on the pathogenic mechanisms of appearance and progression of diabetic neuropathy, having the purpose to reduce the nervous fibre loss) and symptomatic treatment (having the purpose to reduce pain and restore normal physical functioning).

Alpha-lipoic acid (ALA) is a substance that has the ability to decrease the oxidative stress, a key component in the pathogenesis of diabetic neuropathy. Hyperglycaemia 
determines an increased production of free radicals, and its metabolism depletes the endogen antioxidant mechanisms. Oxidative stress leads to an increased neuronal apoptosis explaining the progression of diabetic neuropathy [13]. It was experimentally proved on rodents that ALA reduces lipid peroxidation in a dose-dependent manner [14]. Because it inhibits lipid peroxidation ALA is used in diabetic neuropathy, the nervous fibres, especially at the level of the myelin sheet, having high lipid content. ALA has a proven scavenger effect on lipophilic free radicals [8]. In other experimental studies it was demonstrated that ALA improves blood flow at the level of peripheral nerves and increases nerve conduction [15].

Benfotiamine (S-benzoylthiamine 0-monophoshate, Milgamma) is a synthetic form of vitamin B1 with great lipid solubility. Thiamine is a cofactor of transketolase, an enzyme that forces the metabolism of fructose-6phosphate and gliceraldehide-3-phosphate on the pentose pathway; these two substances transform in pentoso-5phosphates and other sugars that do not produce metabolic alterations [16]. Diabetes mellitus patients have frequently thiamine deficiency, serum levels of thiamine are $75 \%$ lower in diabetes mellitus patients than in non-diabetic persons; one of the factors that are responsible for this values being the increased renal clearance of this vitamin, in type 1 diabetes mellitus patients the elimination is 24 times greater than in non-diabetic persons and in type 2 diabetes mellitus patients, the elimination is 16 times greater [17-20]. The administration of benfotiamine inhibits 3 main pathogenic mechanisms implicated in diabetic neuropathy occurrence, and other microvascular complications: hexosamine pathway, diacylglycerol protein kinase $\mathrm{C}$ pathway and the formation of advanced glycosylation end products [21]. Benfotiamine administered in rodents reduced the inflammatory and neuropathic nociceptive pain [22]. In vitro, in rodents with streptozotocin induced diabetes, the administration of thiamine and Benfotiamine brought back to normal the level of advanced glycosylation end products [23].

Our study was a therapeutic, prospective, monocentric, non-controlled placebo study that had the purpose to evaluate the efficacy of Benfotiamine and ALA, and also the association between the two substances on the clinical progression of DSPDN assessed using the following parameters: Diabetic Neuropathy Symptoms (DNS) score, Neuropathy Disability Score (NDS) and the intensity of lower limb pain on the visual analogue pain scale. We also determined the tolerance to the administered substances and their effect on glycaemic control, expressed by HbAlc.

\section{Experimental part}

\section{Material and method}

We included 120 patients with type 1 or type 2 diabetes mellitus. We applied the following criteria for the patients:

- inclusion criteria: patients that signed the informed consent; patients with ages between 18 and 65; patients with known and confirmed type 1 or type 2 diabetes mellitus; patients with known and confirmed DSPDN by neurological consult in the past; patients with a level of $\mathrm{HbAlc}<10 \%$ in the moment of screening; the intensity of neuropathic pain on the visual analogue pain scale e"2, and the presence of lower limb pain for at leastone hour in the past 3 months; stable antidiabetic treatment in the past 3 months.

- exclusion criteria: other causes of peripheral neuropathy: cirrhosis, B vitamin deficiency, malabsorption, chronic kidney disease with creatinine values $\geq 3 \mathrm{mg} / \mathrm{dL}$, peripheral artery disease, systemic diseases (scleroderma, systemic erythematous lupus, Sjogren syndrome, rheumatoid arthritis), toxicosis (barbiturates, chimiotherapics, HIV therapy, sulphonamides, gentamicin), infectious diseases (septicaemia, influenza, infectious mononucleosis, HIV infection, varicella zoster virus infection); diseases that manifest with pain: zoster zone, trigeminal neuralgia, spinal cord injury, post stroke syndrome [24,25]; myopathy of any cause; significant cardiovascular, pulmonary, hepatic or renal pathology: myocardial infarction or unstable angina in the past 6 months, arrhythmias, cirrhosis, end stage kidney diseases, antioxidant or analgesic treatment in the past 3 months $[24,26-29]$; patients that in the past 3 months used ALA or Benfotiamine.

Study design is presented in Table 1

After informing the patients about the contents of the study, the administered medication and possible adverse effects, and after obtaining their written consent, the patients that fulfilled the established criteria were placed in one of the three therapeutic groups, in order of their evaluation, 40 patients/group. The research was conducted according to the principles of the Helsinki Declaration and with the approbation of the Ethics Commission of the Faculty of Medicine and Pharmacy, University of Oradea.

For every patient the period of observation was 21 weeks. The study started in January 2017 and ended in July 2018. Each patient included was summoned to attend the 4 visits. From the total of 120 patients included in the study, 6 patients were excluded because they did not come to the indicated visits.

The study consisted in the baseline period (that lasted 1 week), the therapeutic period (when Benfotiamine and ALA were administered, and it had a duration of 8 weeks) and the post-therapeutic period (with a duration of 12 weeks). The visits were distributed in the following way: visit 1 in the baseline period, when the screening of patients was made; visit 2, when the patients were randomized in one of the therapeutic groups; visit 3 at the end of the therapeutic period; visit 4 after 12 weeks from the end of the therapeutic period. The baseline period included visit 1 when the patients were examined to establish if they met the inclusion criteria, signed the informed consent and laboratory probes were sampled. In the treatment period, patients were randomized in the 3 therapeutic groups, in successive order, and presented to the visits 2 and 3 from the therapeutic period for the clinical evaluation of DSDPN

Table 1

STUDY DESIGN

\begin{tabular}{|c|c|c|c|}
\hline \multirow{4}{*}{ Period } & \multirow{4}{*}{$\begin{array}{l}\text { Baseline } \\
\text { period }\end{array}$} & Therapeutic period & \multirow{4}{*}{$\begin{array}{l}\text { Post-therapeutic } \\
\text { follow-up period }\end{array}$} \\
\hline & & BENFOTIAMINE: the first group of patients & \\
\hline & & ALA: the second group of patients & \\
\hline & & BENFOTIAMINE+ALA: the third group of patients & \\
\hline Duration & 1 week & 8 weeks & 12 weeks \\
\hline Visit & 1 & 3 & 4 \\
\hline
\end{tabular}


(calculation of DNS score, NDS, pain on the visual analogue pain scale, to fill up the study questionnaires, for monitoring of the safety parameters and reporting the adverse effects). The follow-up period meant that patients should present at visit 4 for the evaluation of the clinical parameters of diabetic neuropathy and monitoring the adverse effects.

Patients that presented to the Diabetes Centre from the Clinical County Emergency Hospital of Oradea beginning with J anuary 3, 2017 for clinical evaluation, were requested the informed consent for the inclusion in the study. From the patients who agreed to enter the study, was collected information regarding demographic data (age, sex, provenience), clinical data (anamnesis, physical examination, medical history, duration of diabetes mellitus, duration of presence of DSPDN, comorbidities), present and past medication. Then, laboratory analysis was performed: $C B C$, liver enzymes, total and direct bilirubin, creatinine, urea, urine analysis and glycated haemoglobin. After analysis of the obtained data the patients who met the inclusion criteria were requested to come one week later and were explained the interval of the next visits.

\section{Efficacy parameters}

The main efficacy parameter was DNS score. The questionnaire is made of 4 questions; every question is attributed 1 point, the minim score being 0 and the maxim score being 4 . A score $\geq 1$ is positive for the presence of DSPDN and higher scores correspond to a more advanced severity of DSPDN. DNS is a method that has a high predictive value regarding the diagnosis of diabetic neuropathy [30]. The secondary efficacy parameters were NDS, the estimation of pain at the level of the lower limbs using the visual analogue pain scale and the estimation made by the patients of the efficacy of the administered medication at the end of the therapeutic period. NDS is a tool for diagnosis of DSPDN with a good accuracy and has the capacity to predict the risk of lower limb ulceration [31]. The method implies the testing of vibratory perception at the level of the lower limbs, the perception of temperature, the perception of pain and of Achilles reflex.

The intensity of the pain was appreciated on the visual analogue pain scale, where the absence of pain was noted with 0 points and the maximum intensity of the pain with 10 points. The patient chose the intensity of pain that he felt the past day. Treatment efficacy was evaluated by the patients with the help of a questionnaire, they had to choose between: very good, moderate or absent efficacy.

\section{Exploratory parameters}

The value of HbAlc was determined at visit 1 , visit 3 , and at the end of the therapeutic study.

\section{Safety parameters}

These were the vital parameters: blood pressure and heart frequency, EKG, laboratory parameters determined at visit 1 and visit 3, CBC, liver enzymes, total and direct bilirubin, urea, and creatinine.

\section{Adverse effects}

There were considered adverse effects any new medical symptoms or the aggravation of a pre-existent symptomatology that appeared during the treatment.

\section{Administered medication}

The medication was administered from visit 2 to visit 3 , for 8 weeks: Benfotiamine tablets of $300 \mathrm{mg}, 1$ tablet/day; ALA tablets of $600 \mathrm{mg}, 1$ tablet/day; the combination Benfotiamine (tablets of $300 \mathrm{mg}, 1$ tablet/day) and ALA (tablets of $600 \mathrm{mg}, 1$ tablet/day).

The statistical analysis was made with Microsoft Excel software for the descriptive part and MedCalc software for the analytical part.

\section{Results and discussions}

Table 2 presents the characteristics of the patients from the 3 therapeutic groups.

\section{Evolution of DNS score}

The evolution of DNS score is presented in Table 3. DNS score, as a result of the treatment administered for 8 weeks, lowered statistically significant in all the treatment groups. In the Benfotiamine group, DNS score lowered statistically significant from 2.48 points to 1.93 points. In the ALA group, DNS score lowered statistically significant from 2.52 points to 1.38 points. In the Benfotiamine and ALA combination group, DNS score lowered statistically significant from 2.50 points to 1.02 points. After the administration of treatment was discontinued, the DNS score values increased, almost reaching the initial values, after 12 weeks. A reduction with more than $50 \%$ of DNS score is considered a good therapeutic response. These therapeutic objectives were achieved in 4 ( $10.53 \%$ of total) patients from the Benfotiamine group, in $10(27.78 \%$ of total) patients from the ALA group, and 26 ( $65 \%$ of total) patients from the Benfotiamine and ALA combination group.

Table 2

CHARACTERISTICS OF THE PATINTS FROM THE THERAPUTHIC GROUPS

\begin{tabular}{|c|c|c|c|c|}
\hline Characteristics & Benfotiamine & ALA & Benfotiamine + ALA & $\mathrm{p}$ \\
\hline Number of patients & 38 & 36 & 40 & \multirow{11}{*}{$>0.05$} \\
\hline Age (years) & $52.4 \pm 10.15$ & $53.1 \pm 9.8$ & $52.4 \pm 11.2$ & \\
\hline $\operatorname{Sex}(\% \operatorname{men})$ & 52.36 & 52.77 & 47.55 & \\
\hline $\mathrm{BMI}\left(\mathrm{kg} / \mathrm{m}^{2}\right)$ & $28.65 \pm 4.7$ & $29.3 \pm 4.2$ & $28.48 \pm 3.9$ & \\
\hline Diabetes type ( $\%$ type 2$)$ & 89.47 & 86.11 & 87.5 & \\
\hline Diabetes duration (years) & $7.8 \pm 4.2$ & $7.3 \pm 4.5$ & $7.5 \pm 4.7$ & \\
\hline DSPDN duration (years) & $3.6 \pm 2.4$ & $3.8 \pm 2.6$ & $4.1 \pm 2.8$ & \\
\hline HbAlc (\%) & $7.2 \pm 1.5$ & $7.4 \pm 1.8$ & $7.5 \pm 1.2$ & \\
\hline Smoking (\%) & 31.58 & 27.78 & 27.50 & \\
\hline Diabetic retinopathy (\%) & 39.47 & 38.89 & 42.50 & \\
\hline Chronic kidney disease (\%) & 36.84 & 30.56 & 37.50 & \\
\hline
\end{tabular}


Table 3

DNS SCORE MODIFICATION

\begin{tabular}{|c|c|c|c|}
\hline \multirow{2}{*}{ DNS score } & \multicolumn{3}{|c|}{ Administered medication } \\
\hline & Benfotiamine & ALA & Benfotimine + ALA \\
\hline \multicolumn{4}{|l|}{ At the 3 visits $(2,3,4)$} \\
\hline Visit 2 & 2.48 & 2.52 & 2.5 \\
\hline Visit 3 & 1.93 & 1.38 & $\begin{array}{c}1.02 \\
p^{*}<0.01, p^{* *}=0.05\end{array}$ \\
\hline Visit 4 & 2.4 & 2.32 & 2.28 \\
\hline \multicolumn{4}{|l|}{ At the end of treatment } \\
\hline DNS score V2 & $2.48 \pm 1.17$ & $2.52 \pm 1.05$ & $2.50=1.18$ \\
\hline DNS score V3 & $1.93 \pm 0.65$ & $1.38 \pm 0.84$ & $1.02 \pm 0.87$ \\
\hline DNS score modification & $\begin{array}{l}0.55 \text { CI 95\% } \\
(0.11-0.98)\end{array}$ & $\begin{array}{l}1.14 \text { CI } 95 \% \\
(0.69-1.58)\end{array}$ & $\begin{array}{l}1.48 \text { CI } 95 \% \\
(1.03-1.98)\end{array}$ \\
\hline Statistical significance & $p<0.05$ & $p<0.01$ & $\mathrm{p}<0.01$ \\
\hline \multicolumn{4}{|c|}{ Therapeutic response (no. of patients/ $\%$ ) } \\
\hline$\geq 50 \%$ reduction & $4 / 10.53$ & $10 / 27.78$ & $26 / 65.00$ \\
\hline
\end{tabular}

\section{Evolution of NDS}

The evolution of NDS in presented in Table 4. NDS lowered statistically significant at visit 3, and at the end of the therapeutic period, in all the 3 treatment groups. After 12 weeks from the discontinuation of Benfotiamine, ALA or Benfotiamine and ALA combination treatment NDS increased to values similar to the initial ones in all the therapeutic groups.

\section{Evolution of pain intensity}

Pain intensity, evaluated on the visual analogue pain scale, lowered statically significant in all the treatment groups. In the Benfotiamine group pain intensity lowered from 5.95 points to 3.8 points, in the ALA group pain intensity lowered from 5.8 to 2.85 points. The greatest reduction of pain intensity was achieved in the Benfotiamine and ALA combination group. After 12 weeks from the treatment discontinuation the pain intensity increased to values that were similar to the initial ones in all the treatment groups. The results are presented in Table 5.
Estimation of treatment efficacy by the patients, glycaemic control, adverse effects

Patients that were treated with Benfotiamine and ALA estimated the efficacy of the treatment as being very good in 35\% of cases, moderate in $55 \%$ of cases and absent in $10 \%$ of cases. Patients from the Benfotiamine group estimated the efficacy of treatment as being very good in $5.26 \%$ of cases, moderate in $63.16 \%$ of cases and absent in $31.58 \%$ of cases. Patients that were in the ALA group estimated the efficacy of treatment as being very good in $25 \%$ of cases, moderate in $58.33 \%$ of cases and absent in $16.67 \%$ of cases. In all of the therapeutic groups there was not observed any $\mathrm{HbAlc}$ statistically significant reduction. In the group of patients treated with Benfotiamine there were not registered any adverse effects, in the group of patients treated with ALA nausea appeared in $5.56 \%$ of cases and dizziness in $2.78 \%$ of cases and in the group of patients treated with Benfotiamine and ALA combination nausea appeared in $7.50 \%$ of cases and dizziness in $2.50 \%$ of cases. The adverse effects had a minor intensity and did not lead to the discontinuation of treatment. These results are presented in Table 6 .

Table 4

NDS MODIFICATION

\begin{tabular}{|c|c|c|c|}
\hline \multirow{2}{*}{ NDS } & \multicolumn{3}{|c|}{ Administered medication } \\
\hline & Benfotiamine & $\overline{\mathrm{ALA}}$ & Benfotiamine + ALA \\
\hline \multicolumn{4}{|l|}{ At the 3 visits $(2,3,4)$} \\
\hline Visit 2 & 5.1 & 5.17 & 5.28 \\
\hline Visit 3 & 4.58 & 3.72 & $\begin{array}{c}3.46 \\
p^{*}<0.01, p^{* *}<0.05\end{array}$ \\
\hline Visit 4 & 4.98 & 4.83 & 4.86 \\
\hline \multicolumn{4}{|l|}{ At the end of treatment } \\
\hline NDS V2 & $5.10 \pm 2.59$ & $5.17 \pm 2.86$ & $5.28 \pm 2.96$ \\
\hline NDS V3 & $4.58 \pm 2.81$ & $3.72 \pm 2.61$ & $3.46 \pm 2.98$ \\
\hline NDS modification & $\begin{array}{l}0.52 \mathrm{CP} 95 \% \\
(0.71-1.75)\end{array}$ & $\begin{array}{l}1.45 \mathrm{CI} 95 \% \\
(0.16-2.73)\end{array}$ & $\begin{array}{l}1.82 \mathrm{CI} 95 \% \\
(0.49-3.14)\end{array}$ \\
\hline Statistical significance & $p<0.05$ & $\mathrm{p}<0.01$ & $\mathrm{p}<0.01$ \\
\hline
\end{tabular}




\begin{tabular}{|c|c|c|c|}
\hline \multirow{2}{*}{$\begin{array}{l}\text { Pain intensity on the visual } \\
\text { analogue pain scale }\end{array}$} & \multicolumn{3}{|c|}{ Administered medication } \\
\hline & Benfotiamine & ALA & Benfotiamine + ALA \\
\hline \multicolumn{4}{|l|}{ At the 3 visits $(2,3,4)$} \\
\hline Visit 2 & 5.95 & 5.8 & 5.75 \\
\hline Visit 3 & 3.8 & 2.85 & $\begin{array}{c}1.95 \\
p^{*}<0.01, p^{* *}<0.05\end{array}$ \\
\hline Visit 4 & 5.84 & 5.62 & 5.28 \\
\hline \multicolumn{4}{|l|}{ At the end of treatment } \\
\hline Pain intensity V2 & $5.95 \pm 2.25$ & $5.8 \pm 2.5$ & $5.75 \pm 2.4$ \\
\hline Pain intensity V3 & $3.8 \pm 1.6$ & $2.85 \pm 1.75$ & $1.95 \pm 1.85$ \\
\hline Pain intensity modification & $\begin{array}{c}2.15 \mathrm{CI} 95 \% \\
(1.25-3.04) \\
\end{array}$ & $\begin{array}{l}2.85 \text { CI } 95 \% \\
(1.93-3.96) \\
\end{array}$ & $\begin{array}{l}3.8 \text { CI 95\% } \\
(2.84-4.75) \\
\end{array}$ \\
\hline Statistical significance & $p<0.0001$ & $\mathrm{p}=0.0001$ & $\mathrm{p}=0.0001$ \\
\hline
\end{tabular}

Table 5

PAIN INTENSITY

MODIFICATION AT THE

END OF TREATMENT

\begin{tabular}{|c|c|c|c|}
\hline \multirow{2}{*}{ Parameter } & \multicolumn{3}{|c|}{ Administered medication ( $\%$ of patients) } \\
\hline & Benfotiamine & ALA & Benfotiamine + ALA \\
\hline \multicolumn{4}{|c|}{ Estimation of treatment efficacy } \\
\hline Very good & 5.26 & 25.00 & 35.00 \\
\hline Moderate & 63.16 & 58.33 & 55.00 \\
\hline Absent & 31.58 & 16.67 & 10.00 \\
\hline \multicolumn{4}{|l|}{ Glycaemic control: $\mathrm{HbAlc}$} \\
\hline $\mathrm{V} 2$ & $7.2 \pm 1.5$ & $7.4 \pm 1.8$ & $7.5 \pm 1.2$ \\
\hline V3 & $7 \pm 1.8$ & $7.25 \pm 1.6$ & $7.4 \pm 1.7$ \\
\hline Modification & $\begin{array}{c}0.2 \mathrm{CI} 95 \%(0.55- \\
0.95)\end{array}$ & $\begin{array}{l}0.15 \mathrm{CI} 95 \% \\
(0.65-0.95)\end{array}$ & $\begin{array}{l}0.1 \mathrm{CI} 95 \% \\
(0.55-0.75)\end{array}$ \\
\hline Statistical significance & NS & NS & NS \\
\hline \multicolumn{4}{|c|}{ Adverse effects (number $/ \%$ ) } \\
\hline Nausea & - & $2 / 5.56$ & $3 / 7.50$ \\
\hline Dizziness & - & $1 / 2.78$ & $1 / 2.50$ \\
\hline
\end{tabular}

Table 6

GLOBAL ESTIMATION OF

EFFICACY, GLYCEMIC CONTROL AND ADVERSE EFFECTS
Benfotiamine is a synthetic form of vitamin $B 1$, thiamine that has an increased lipid solubility that gives it a higher bioavailability. The substance acts through complex mechanisms that determine that the precursors of advanced glycosylation end products to be metabolised on the pentosophospate pathway, a pathway that inhibits the accumulation of these products [32]. The efficacy of Benfotiamine in reducing diabetic neuropathy symptomatology and improving the specific parameters for the peripheral sensibility was evaluated in numerous studies. Benfotiamine, administered in different doses, for 6 weeks, significantly reduced the intensity of neuropathic pain and improved the vibration perception threshold, the best results being achieved in patients that received a high dose of Benfotiamine [33]. In the BENDIP study were evaluated 165 patients with DSPDN, they were administered either Benfotiamine for 6 weeks in a dose of $300 \mathrm{mg} /$ day or Benfotiamine $600 \mathrm{mg} /$ day or placebo medication. DNS score improved significantly in patients that received Benfotiamine compared to the patients that received placebo [34]. However, there are studies that concluded that Benfotiamine is not efficient in DSPDN, at least regarding the improving of nerve conduction. In a study, Benfotiamine administered in a dosage of $300 \mathrm{mg} /$ day for 24 months did not improve significantly the nerve conduction [35]. It is important to specify that there are not any meta-analyses regarding the efficacy of Benfotiamine in the treatment of DSPDN.

In our study, Benfotiamine (administered in a dose of $300 \mathrm{mg} /$ day for 8 weeks) statistically significant reduced DNS score, NDS and the intensity of pain on the visual analogue pain scale, but few patients obtained a reduction $\geq 50 \%$ of DNS score.

ALA administered in a dose of $600 \mathrm{mg} /$ day, for 5 w eeks, in the SYDNEY 2 study, produced a reduction with $51 \%$ of DNS score; in the groups where the dosage was $1200 \mathrm{mg} /$ day respectively $1800 \mathrm{mg} /$ day, the reduction of DNS score was $48 \%$ and respectively $52 \%$; this leads to the conclusion that the optimum dosage was $600 \mathrm{mg} /$ day, having the greatest efficacy with the lowest frequency of side effects [36]. A study conducted in Korea, where ALA was administered for 8 weeks in a dosage of $600 \mathrm{mg} /$ day, demonstrated a good efficacy with the reduction of total symptoms with at least $30 \%$ in $71.4 \%$ of the patients, and the patients evaluated the efficacy of the drug as being good in $76.3 \%$ of cases [37]. In our study, was achieved a reduction $\geq 0 \%$ of DNS score in $27.78 \%$ on ALA therapy, with the remark that if the threshold of DNS score reduction is lowered at $30 \%, 52.77 \%$ of patients on ALA therapy fall under this threshold.

The efficacy of ALA therapy was evaluated in the metaanalysis. One of these studies concludes that ALA 
administered intravenously in a dosage of $600 \mathrm{mg} /$ day, for 3-5 weeks, is efficient in reducing the symptomatology of DSPDN [38]. Despite this, regarding the administration of ALA orally, the authors of the meta-analysis state that the majority of the included patients from the analysed studies obtained a reduction of $\geq 50 \%$ of the total symptoms score, but if this score is compared to the control groups where placebo was administered - the reduction is not higher than 30\% [38]. After the discontinuation of ALA in our study, at 12 weeks, the values of DNS score, NDS, and the pain intensity on the visual analogue score came back to the initial values. In another study, ALA was administered to 45 patients with DSPDN, in a dosage of $600 \mathrm{mg}$ orally, for 4 weeks; the patients that responded to the treatment (had a significant reduction of the symptoms score) were divided in two groups: a group where ALA treatment was continued for 16 weeks and a group where the ALA treatment was stopped [39]. In the group where ALA was stopped, the use of analgesic medication for neuropathic pain increased significantly.

Unfortunately, in literature we did not identify studies that evaluate the effect of the combination of ALA and Benfotiamine on DSPDN. Our study proved that the greatest improvement regarding DNS score, NDS and the pain intensity on the visual analogue scale was achieved in the group of patients that were given Benfotiamine and ALA treatment. The most important observation in the medical literature is that $A L A$ acts not only on the mechanisms that maintain and lead to the progression of DSPDN, but also improves the symptoms, meaning that it plays a double role of pathogenic and symptomatic treatment [40].

\section{Conclusions}

The administration of Benfotiamine orally in a dosage of $300 \mathrm{mg} /$ day for 8 weeks or ALA orally in a dosage of 600 $\mathrm{mg} /$ day, for 8 weeks, or the combination of the two substances in patients with DSPDN lead to a statistically significant reduction of DNS score, NDS and the pain intensity on the visual analogue pain scale. The best results regarding the modification of these parameters were achieved through the combined Benfotiamine and ALA treatment. The discontinuation of pathogenic treatment leads to losing all the improvements of these parameters, which means that the pathogenic treatment in DSPDN needs to be administered on long-term.

\section{References}

1.J USTER-SWITLYK, K., SMITH, A.G., F1000Res., 5, 2016, p. 738.

2.KAUR, S., PANDHI, P., DUTTA, P., Annals Neurosci., 18, nr. 4, 2011, p. 168.

3.CALLAGHAN, B.C., CHENG, H., STABLES, C.L., SMITH, A.L., FELDMAN, E.L., Lancet Neurol., 11, nr. 6, 2012, p. 521.

4.GUJA, C., BOTNARIU, G., CERGHIZAN, A., DINCA, M., POPA, A., SUCIU, G., Diab. Res. Clin. Pract., 120, nr. Suppl. 1, 2016, p. S101.

5.MOTA, M., POPA, S.G., MOTA, E., MITREA, A., CATRINOIU, D., CHETA, D.M., GUJ A, C., HANCU, N., IONESCU-TIRGOVISTE, C., LICHIARDOPOL, R., MIHAI, B.M., POPA, A.R., ZETU, C., BALA, C.G., ROMAN, G., SERAFINCEANU, C., SERBAN, V., TIMAR, R., VERESIU, I.A., VLAD, A.R., J. Diabetes, 8, nr. 3, 2016, p. 336. DOI: 10.1111/1753-0407.12297 6.POPA, S., MOTA, M., POPA, A., MOTA, E., SERAFINCEANU, C., GUJA, C., CATRINOIU, D., HANCU, N., LICHIARDOPOL, R., BALA, C., ROMAN, G., RADULIAN, G., TIMAR, R., MIHAI, B., J. Endocrinol. Invest., 39, nr. 9, 2016, p. 1045. DOI: 10.1007/s40618-016-0470-4

7.GUJA, C., BOTNARIU, G., CERGHIZAN, A., DINCA, M., POPA, A., SUCIU, G., Diabetes mellitus as cardiovascular disease. International Conference on Interdisciplinary Management of Diabetes Mellitus and its Complications, 2016, p. 255. $2^{\text {nd }}$ International Conference on Interdisciplinary Management of Diabetes Mellitus and its Complications, INTERDIAB, Bucharest, Romania.

REV.CHIM.(Bucharest) $70 \bullet$ No. $9 \bullet 2019$

http://www.revistadechimie.ro
8.POP-BUSUI, R., Diabetes Care, 40, nr. 1, 2017, p. 136. 9.YAGIHASHI, S., MIZUKAMI, H., SUGIMOTO, K., J. Diabetes Investig., 2, nr. 1, 2011, p. 18.

10.SUGIMOTO, K., NISHIZAWA, Y., HORIUCHI, S., Diabetologia, 40, 1997, p. 1380.

11.SZASZ, F., LEVAI, C., NAVOLAN, D., FARCAS, S., ANDREESCU, N., BIRSASTEANU, F., MEHEDINTU, C., IONESCU, C.A., BOHILTEA, R., CARABINEANU, A., NEMESCU, D., SIMU, S., STOIAN, D., Rev. Chim.(Bucharest), 69, no. 2, 2018, p. 529.

12.BERCEANU, C., TETILEANU, A.V., OFITERU A.-M., BRATILA, E., MEHEDINTU, C., VOICU, N.L., SZASZ, F.A., BERCEANU, S., VLADAREANU, S., NAVOLAN, D.-B., Rom. J. Morphol. Embryol., 59, nr. 1, 2018, p. 175.

13.VALLIANOU, N., EVANGELOPOULOS, A., KOUTALAS, P., RDS, 6, nr.4, 2009, p. 230.

14.NICKANDER, K.K., MCPHEE, B.R., LOW, P.A., TRITSCHLER, H., FREE RADIC. BIOL. MED., 21, nr. 5, 1996, p.631.

15.NAGAMATSU, M., NICKLANDER, K.K., SCHMELZER, J.B., RAYA, A., WITTROCK, D.A., TRISCHLER, H.J., LOW P.A., Diabetes Care, 18, 1995, p. 1160.

16.PACAL, L., KURICOVA, K., KANKOVA, K., World J. Diabetes, 4, nr. 3, 2014, p. 288.

17.THORNALLEY, P.J., JAHAN, I., NG, R., J. Biochem., 129, 2001, p. 543.

18.ROMAN, G., BALA, C., CRETEANU, G., GRAUR, M., MOROSANU, M., AMORIN, P., PIRCALABOIU, L., RADULIAN, G., TIMAR, R., CADARIU, AA. Acta Endocrinol.-Bucharest., 11, nr. 1, 2015, p. 64. DOI: 10.4183/ aeb.2015.64

19.GUJA, C., IOACARA, S., CATRINOIU, D., NEGRISANU, G., POPA, A. Interdisciplinary Approaches in Diabetic Chronic Kidney Disease, 2015, p. 230. $1^{\text {st }}$ International Conference on Interdisciplinary Management of Diabetes Mellitus and its Complications, INTERDIAB, Bucharest, Romania.

20.HUSSEIN, S., POPA, A.R., ALBU, M.S., Diabetologia, 44, nr. Supplement 1, 2001, p. A138.

21.HAMMES, H.P., DU, X., EDELSTEIN, D., TAGUCAI, T., MATSUMURA, T., JU, Q., LIN, J., BIERHAUS, A., NAWROTH, P., HANNAK, D., NEUMAIER, M., BERGFELD, R., GIARDINO, I., BROW NLEE, M., Nat. Med., 9, nr. 3, 2003, p. 294.

22.SANCHEZ-RAMIREZ, G.M., CARAM-SALAS, N.L., ROCHA-GONZALEZ, H.I., VIDAL-CANTU, G.C., MEDINA-SANTILLAN, R., REYES-GARCIA, G., GRANADOS-SOTO, V., Eur. J. Pharmacol., 530, nr. 1-2, 2006, p. 48.

23.KARACHALIAS, N., BABAEI-JADIDI, R., KUPICH, C., AHMED, N., THORNALLEY, P.J., Ann N. Y. Acad Sci., 1043, 2005, p. 777.

24.FODOR, K., TIT, D.M., PASCA, B., BUSTEA, C., UIVAROSAN, D., ENDRES, L., IOVAN, C., ABDEL-DAIM, M., BUNGAU S., Oxid. Med. Cell. Longev., 2018, 2018, ID 4147320, 10 pages. https://doi.org/10.1155/ 2018/4147320

25.ABDEL-DAIM, M.M., ZAKHARY, N.I., ALEYA, L., BUNGAU, S.G., BOHARA, R.A., SIDDIQI, N.J., Oxidat. Med. Cell. Longev., 2018, 2018, ID 2098123, 2 pages, 2018. https://doi:10.1155/2018/2098123

26.DIACONU, C.C., DRAGOI, C.M., BRATU, O.G., NEAGU, T.P., PANTEA STOIAN, A., COBELSCHI, P.C., NICOLAE, A.C., IANCU, M.A., HAINAROSIE, R., STANESCU, A.M.A., SOCEA, B., Farmacia, 2018, 66, nr. 3, 2018, p. 408.

27.DIACONU, C.C., MANEA, M., IANCU, M.A., STANESCU, A.M.A., SOCEA, B., SPINU, D.A., MARCU, D., BRATU, O.G., Rev. Chim.(Bucharest), 69, no. 5, 2018, p. 1071.

28.DIACONU, C.C., STANESCU, A.M.A., PANTEA STOIAN, A., TINCU, R.C., COBILINSCHI, C., DRAGOMIRESCU, R.I.F., SOCEA, B., SPINU, D.A., MARCU, D., SOCEA, L.I., BRATU, O.G., Rev. Chim.(Bucharest), 69, no. 6, 2018, p. 1367.

29.RADULESCU, D., BALCANGIU STROESCU, A., PRICOP, C., GEAVLETE, B., NEGREI, C., BRATU, O., GINGHINA, O., VACAROIU, I., Rev. Chim.(Bucharest), 68, no. 1, 2017, p. 52.

30.MEIJER, J.W., SMIT, A.J ., SONDEREN, E.V., GROOTHOFF, J.W., EISMA, W.H., LINKS, T.P., Diabet Med., 19, nr. 11, 2002, p. 962. 
31.KASZNICKI, J., Archives Medical Sci.,/ 10, nr. 2, 2014, p. 345

32.BALAKUMAR, P., ROHILLA, A., KRISHAN, P., SOLAIRAJ, P., THANGATHIRUPATHI, A., Pharmacol Res., 61, nr. 6, 2010, p. 482.

33.WINKLER, G., PAL, B., NAGYBEGANYI, E., ORY, I., POROCHNAVEC, M., KEMPLER, P., Arzneimittelforschung, 49, nr. 3, 1999, p. 220.

34.TESFAYE, S., MALIK, R., WARD, J.D., Diabetologia, 37, nr. 9, p. 847. 35.FRASER, D.A., DIEP, L.M., HOVDEN, I.A., Diabetes Care, 35, nr. 5, 2012, p. 1095.

36.ZIEGLER, D., AMETOV, A., BARINOV, A., Diabetes Care, 29, nr. 11, 2006, p. 2365.
37.HAHM, J.R., KIM, B.J ., KIM K.W., J. Diabetes Complications, 18, nr. 2, 2004, p.79.

38.MIJ NHOUT, G.S., KOLLEN, B.J ., ALKHALAF, A., KLEEFSTRA, N., BILO, H.J ., Int. J. Endocrinol., 2012, ID. 456279.

39.GARCIA-ALCALA, H., SANTOS, VICHIDO, C.I., ISLAS, MACEDO, S., GENESTIER-TAMBORERO, C.N., MINUTTI-PALACIOS, M., HIRALES, TAMEZ, O., et al., J. Diabetes Res., 2015, ID 189857.

40.NGUYEN, N., TAKEMOT, J.K., Pharm. Sci., 21, nr. 1, 2018, p. $192 \mathrm{~s}$.

Manuscript received: 7.01 .2019 